\title{
Education Course Syllabus Development, Thai Language Major according to Buddhism Way of Thailand
}

\author{
Chaiwat Waree ${ }^{1}$ \\ ${ }^{1}$ Faculty of Education, Suan Sunandha Rajabhat University, Bangkok, Thailand \\ Correspondence: Chaiwat Waree, Faculty of Education, Suan Sunandha Rajabhat University, Bangkok, Thailand. \\ Tel: 66-860-775-746. E-mail: chaiwat.wa@ssru.ac.th
}

Received: July 3, 2015 Accepted: August 7, 2015 Online Published: December 29, 2015

doi:10.5539/ies.v9n1p123 URL: http://dx.doi.org/10.5539/ies.v9n1p123

\begin{abstract}
This research aims to develop Education Course Syllabus, Thai language major, according to Buddhism way of Thailand by using Taba's Approach and to evaluate the efficiency of Education Course Syllabus, Thai language major, according to Buddhism way of Thailand. This research was conducted according to research and development format and its operation was divided into 2 phases including: Phase 1: Education Course Syllabus Development, Thai language major, according to Buddhism way of Thailand; Phase 2: Evaluation on efficiency of Course Syllabus, Thai language major, according to Buddhism way of Thailand conducted by the expert. The results showed that the elements of Education Course Syllabus, Thai language major, according to Buddhism way of Thailand were as follows: syllabus principles and objectives, syllabus structure, educational management plan, course description, criteria, assessment, and Curriculum Quality Assurance. The result of the evaluation on efficiency of Course Syllabus, Thai language major, according to Buddhism way of Thailand conducted by the expert showed that the quality of this syllabus was, in overall, in the highest level at mean $=4.62$ and S.D. $=$ 0.42 .
\end{abstract}

Keywords: course syllabus, curriculum, Thai language major, Buddhism way of Thailand, higher education, education students

\section{Introduction}

\subsection{Introduce the Problem}

Currently, global society aims to develop itself to be progressed rapidly leading to competitive society on economy and technology. In addition, technological advancement of the world in new millennium also influences on social and economic changing of all countries even Thailand. As a result, it is necessary to improve the national education that is considered as the important mechanism for developing the quality of Thailand's education in order to make Thai people to be good people with good intellect, happiness, and abilities for competition and creative cooperation in the world stage (Ministry of Education, 2002). The government and agencies related to educational management of Thailand should reform Thai education to be consistent with the wind of change of current world in order to obtain the human resource with diverse abilities. Human is considered as the most important cause and result of national development. As a result, competency development of all Thai people is started from their birth to death in order to make them to seek for knowledge, know how to think and analyze by using scientific reasons as well as to make them have concept, imagination, and creativity. Education is the process aiming to develop humans to be good quality persons with intellectual, mental, physical, and social development in order to reinforce self-development, economic and social progress. As a result, the learner is the ultimate goal of educational process development (Leetheera, 2006). This fact is consistent with the statement provided that education is the method to make people have knowledge and abilities for becoming the wise and reasonable persons who were thinkable, able to solve problems, on intellectually, mentally, physically, and socially developed, able to seek for knowledge to develop themselves and their occupation. Finally, education will be able to make all people to know how to live and depend on one another as well as able to enable them to adjust themselves with occurred changing that was the major goal of national development (Pongpaibul, 1997).

National Education Act B.E. 2542 defined education as a learning process that accelerates the prosperous growth of individuals and society. Such development is achieved through the transference of knowledge, training, the 
preservation of culture, the creation of academic advancement and knowledge, the promotion of the effective management of the learning environment, and the support of lifelong learning. The ultimate aims of education are to transform Thai citizens into perfect human beings, having good health, wholesome minds, intelligence, knowledge, morality, good behavior and cultural life. Educational process for developing humans and society through training, cultural inheritance, and academic advancement and they must be able to live with other people happily (Ministry of Education, 2002).

Thai language is official language of Thailand that is important for all Thai people. In addition to being a communication tool for making understanding, Thai language is also the tool expressing Thainess and cultural heritage. Moreover, it is also the important tool leading to learning and knowledge seeking as well as the foundation for learning other languages according to the speech of Her Royal Highness Princess Maha Chakri Sirindhorn regarding education as shown below: (Debaratanarajasuda, 1999). "...education influencing on national development. As a result, the instruction of Thai language should be provided from primary school in order to enable learners to have sufficient knowledge and abilities for living and have basic education for further education. As a result, abilities and understanding in Thai language should be in good level. I used to hear someone said that people who are excellent in mathematics and science often have poor language skills while people who have excellent language skills often have poor understanding on mathematics and science. However, what I have been seen is not true. What I have been perceived is that people with poor language skills are always poor with other subjects because have poor understanding in language so it's hard to teach them to understand completely..."

The above speech of Her Royal Highness Princess Maha Chakri Sirindhorn represented the speech of current education and Royal Highness Princess Maha Chakri Sirindhorn also considered language as the important tool leading to learning. Moreover, she also kindly provided a speech on Thai language promotion and maintenance as follows:

"Thai language instruction is very important in motivating and promoting learners to have pride and values in using correct Thai language. As a result, it is proper to seek for the guidelines for promoting Thai instruction to be interesting and fun. We are able to promote Thai people's knowledge tank by using Thai language as the media for promoting and supporting learners to love reading and seeking for additional knowledge. This will reinforce students to seek for knowledge and use Thai language correctly and properly that is the very important factor for national development. All people related to Thai language instruction should pay attention to effective Thai language instruction in order to enable learners to have correct knowledge on Thai language and love Thai language."

National Thai Language Day is on the 29th date of July of every year and Thai government declared such day as the important day in 1999 for reminding an event occurred on July 29th, 1962, when His Majesty King Bhumibol Adulyadej participating in the discussion on "Problems in Thai Usage" with some experts at the Faculty of Arts, Chulalongkorn University. There was a part of royal speech stated that "...We are fortunate that we have had our own unique language since ancient times. It should therefore be carefully preserved. This can be accomplished in several ways. The purity of pronunciation should be maintained with great accuracy. Words should be used appropriately in sentences. The key issue is the richness of the Thai language. We should not think that the Thai language is somehow inadequate and that we frequently need to create new words. Although some new words may be necessary for technical or academic usage, most words should remain simple. We should use the words that already exist and not add complications by creating new words."

\subsection{Explore Importance of the Problem}

According to the King's speech on Thai language during 1962-2008, Academic Network for Community Happiness Observation and Research of Assumption (ABAC) University conducted a survey research on "Knowledge and Understanding of Thai People on National Thai Language Day and Problems in Thai Usage". The data was collected from 2, 452 samples with the age of 18 years and over who were living in Bangkok and surroundings. The results showed that $21.5 \%$ of them had never known that there are 44 letters of Thai language and $86.7 \%$ of them had never known how many vowels of Thai language are (21 vowels). In addition, $73.7 \%$ of them had never known how many intonation marks of Thai language are (4 tonal marks 5 tones) and $92.4 \%$ of them had never know what prose is (a form of language that exhibits a grammatical structure and a natural flow of speech rather than a rhythmic structure) while $89.6 \%$ of them had never known what verse is (verse is formally a single metrical line in a poetic composition).

For reinforcing learners to have knowledge and abilities in Thai language for using as the tools for learning other subjects, since all Rajabhat Universities in Thailand recognize the importance of Thai language, they provide 
Thai language instruction for the first year students as the first learning group used by the universities as the foundation for preparing instructional management to all students in all faculties in order to build the foundation of reading, thinking, and using as the further strategies.

In the Seminar for analyzing the curriculum and determining the Thai language curriculum framework of Rajabhat Universities, the Curriculum Development Center indicated that the current Thai language curriculum aims to enable the learners to have listening, speaking, reading, and writing skills consistently by emphasizing on knowledge and understanding in advanced Thai language. The learners must love reading, and be fostered with desirable characteristics for learning Thai language, literature, and national culture (Sakdanarong, 1996).

From the operation of Thai language instruction according to the curriculum of Rajabhat Universities, it was found that Thai language is currently the language with the highest level of criticism. Although Thai language is defined as the prescribed course of Education Course Syllabus of Rajabhat Universities that all students are required to study, it was found that the learning achievement of Thai language instruction of students was quite low and classified in unsatisfied level. From this research, it was found that the mostly found problems on Thai usage of students were incorrect word choice, wrong pronunciation of letters, vowels, intonation marks, and diphthong. In addition, there are some foreign languages used as the substitutes of Thai words. For writing, it was found that most students write Thai words wrongly because they write Thai words upon pronunciation and they also use some short terms sued in specific groups (Vihokto, 2009) From the study of Ministry of University Affairs conducting regression analysis with the evaluation's results, it was found that The advancement rate of Thai language was quite low or at 1\% that was unsatisfying (Ministry of University Affairs, 2001). In addition, the research of Department of Curriculum and Instruction Development also found that Thai language was disliked by most students due to its difficult contents, teacher's instruction, attitude of students, and behaviors of students. Moreover, students also considered that instruction of Thai language on Thai grammar, verse, and literature was not useful for daily life therefore they paid no attention to the importance of Thai language.

The second desirable skills and characteristics according to Education Course Syllabus of Suan Sunandha Rajabhat University or language skills identifying that the learners had communication skills and abilities for communicating with other people correctly and properly. They were confident and had better speaking and thinking skills Education Course Syllabus of Suan Sunandha Rajabhat University (Faculty of Education, 2006).

Way of life and culture of Thai people has been instructed by Buddhist teaching since the first establishment of Thailand. It could be said that Buddhist way is the cultural way of most Thai people until it turns to be the uniqueness that is accepted globally. Buddhism is the knowledge emphasizing on enabling humans to understand nature of the world and life. Consequently, humans would be able to live their lives correctly and properly, i.e., having well-being and pure life. As a result, the individuals who study and comply with Buddhist teaching will be happy and able to make surrounding people and society happy together. Buddhist teaching is the educational system divided into 3 elements called Three Studies (Morality, Concentration, and Wisdom) that is the training system leading to behavioral, physical, mental, and intellectual development. As a result, Three Studies cover all aspects of living from easy ones to complex ones. Consequently, it is the most complete education system enabling people to be god, clever, and happy.

In ancient times, children children's education based on Buddhist teaching and all children held the Buddhist teaching as their way of life according to the good Buddhist way for making merit, observing the precepts, practicing the Dharmma, listening to Dharmma, practicing themselves to eliminate lust. Their daily life was close and related to temples and the temples are the important learning centers of the community. Buddhist Holy Day was the important day for their spirit because it was the day of making merit. In Buddhist Holy Day, Buddhists stop performing all bad or inimical working, for example, omitting animal killing, and omitting all vices, etc. Some Buddhists have strong faith towards Buddhist Holy Day therefore they worn white dress and held eight commandments. In free time, they discussed Dhamma altogether and practiced themselves according to Buddha's teaching. Children saw the adults as their models therefore they complied with those practices leading to pleasant society. When considering on the new generations who are taught by western knowledge, current Thai people live their lives distantly from Buddhist teaching, temples, and religion. Nowadays, if we ask Thai people when the Buddhist Holy Day is, most of them would be speechless with no answer because they pay no attention to this day. Nowadays, it is the proper time that Buddhists should hold the Buddhist teaching as the principles of their way of life for having beautiful life and maintaining the Buddhist teaching that is the national treasure and the foundation of Thailand from the ancient times.

Since the researcher considered on such importance, the researcher prepared the plan for developing Education Course Syllabus, Thai language major, according to Buddhism way of Thailand as the guidelines for developing 
curriculum and reforming education by holding the suitable principles, theories, and techniques with Thai context because the true practice for educational reform is preserving the good and identical existing guidelines. However, some guidelines or processes must be adjusted and amended to be modern and consistent with changing social and economic conditions.

\subsection{State Hypotheses and Their Correspondence to Research Design}

1) To develop Education Course Syllabus, Thai language major, according to Buddhism way of Thailand.

2) To evaluate the efficiency of Education Course Syllabus, Thai language major, according to Buddhism way of Thailand.

\section{Method}

\subsection{Scope of Research}

The target group of this research was 5 educational supervisors and administrators who were skillful in instructional management of Thai language obtained from using purposive sampling. They were responsible for managing instruction of Thai language on curriculum development of Suan Sunandha Rajabhat University.

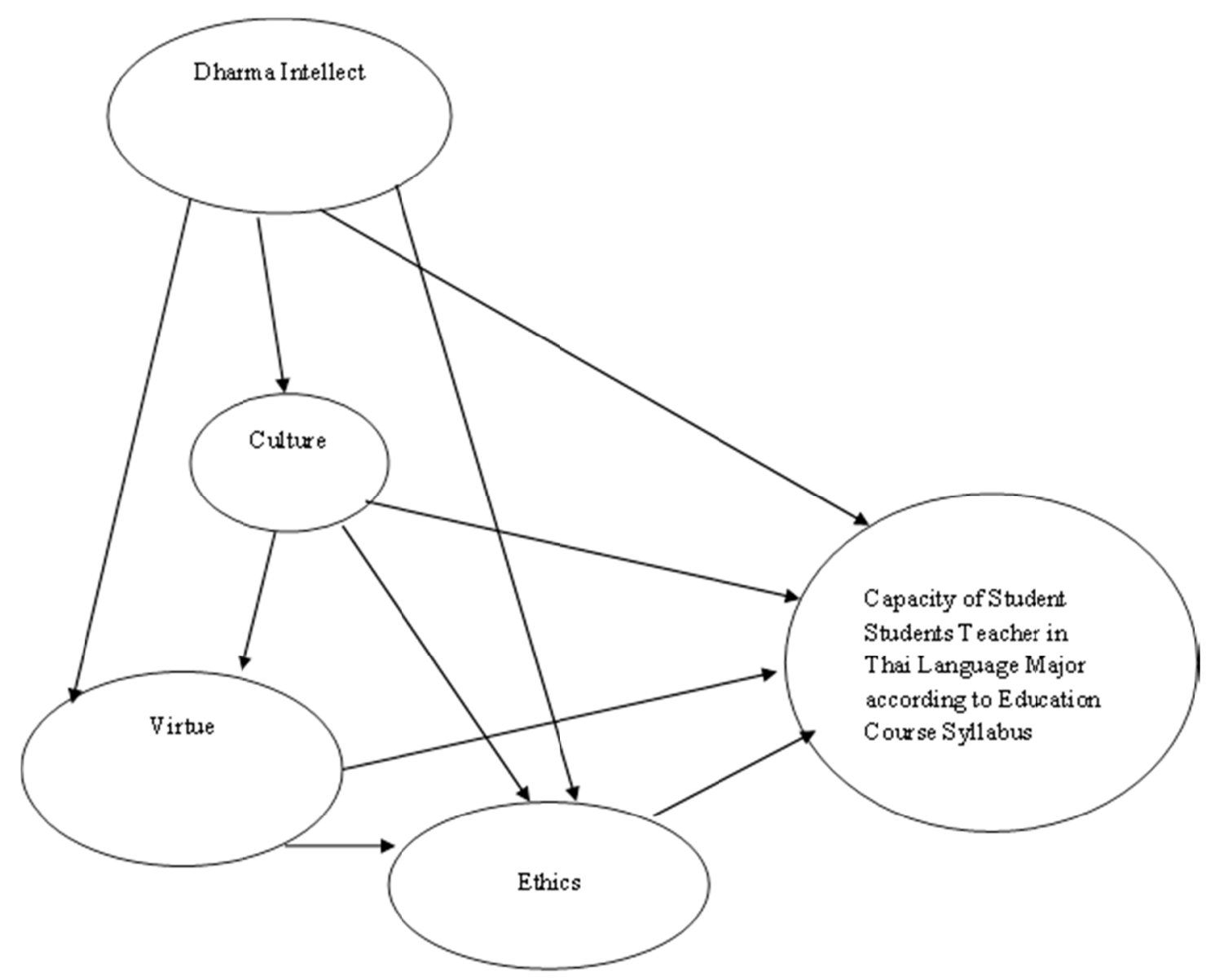

Figure 1. Assumptive or hypothesis model of the student's capacity according to Education Course Syllabus

Factors affecting the capacity of students teacher in Thai language major according to Education Course Syllabus are Dharmar Intellect, culture, virtue and ethics.

\subsection{Expected Benefits}

1) To obtain the guidelines on learning management for student teachers studying in Thai major as the prototype curriculum.

2) Knowledge obtained from this research would be useful for teachers or anyone interested to develop Education Course Syllabus of other majors. 


\subsection{Research Process}

Development of Education Course Syllabus, Thai language major, according to Buddhism way of Thailand was conducted by using Taba's Approach divided into 7 stages as follows:

I) Diagnose demands obtained from conducting the structural interview with 10 Thai language teachers with experience on Thai language teaching not less than 5 years and students from faculty of Education who passed Thai language learning for at least 1 course for determining the curriculum.

II) Determine the curriculum objectives and learning objectives from analyzing basic data.

1) Submit the draft of curriculum objectives and learning objectives to the experts included with 5 curriculum developers and 5 educators for evaluating.

2) Obtain the results, approval, and suggestions of the draft evaluation from the experts. Amend some statements to explain learning behavior properly.

III) Select curriculum's contents

1) Outline the contents from analyzing basic data document on Thai language, cooperative learning management, and basic data analysis. The determined contents must be consistent with learning objectives and the learner group. For selection, the following issues should be considered:

Issue 1: The contents must provide learners knowledge on background of Thai language.

Issue 2: The contents must enable learners to learn the guidelines for developing desirable characteristics for using Thai language in various aspects.

2) Submit the selected draft to the experts for evaluating and the experts are consisted of 5 curriculum and Thai language instructional developers.

3) Obtain the results, approval, and suggestions of the draft evaluation from the experts. Amend some statements to be correct and add some contents.

\section{IV) Contents ordering}

1) Outline the contents by ordering the selected contents in section 3 to manage the contents to meet with determined learning objectives. Determine proper duration of each content properly by considering on its continuity, difficulty, maturity, abilities, and interest of learners.

2) Submit the ordered contents to the experts consisted of 5 curriculum and Thai language instructional developers for evaluating.

3) Obtain the evaluation results on content ordering from the experts and those results were consistent in good level.

V) Select experiences

1) Outline learning experience by selecting from learning experiences and the related persons or teachers must select learning experience to be consistent with subject contents and curriculum objectives by emphasizing on student-centered instruction process and instruction management according to Buddhism way of Thailand, for example, self-study, group discussion, and cooperative instruction, by exchanging knowledge, learning, and helping one another.

2) Submit the draft of selected learning experience to the experts consisted of 5 curriculum developers for evaluating.

3) Obtain the results of evaluation from the experts and the experts agreed with the draft in good level.

VI) Order stages, amend, and improve the learning experiences by considering on contents, continuity, and abilities of the learners for providing proper training.

VII) Determine what to be evaluated and evaluation methods as follows: (1) what to be evaluated, i.e., Education Course Syllabus, Thai language major, according to Buddhism way of Thailand consisted of curriculum contents, curriculum resources, curriculum management, and results obtained from curriculum management; (2) methods for evaluating Education Course Syllabus, Thai language major, according to Buddhism way of Thailand, i.e., evaluated nu the experts, evaluated by 5-rating scale questionnaire asking about quality of training curriculum. The quality of questionnaire on content validity was analyzed by analyzing the consistency of evaluation checklist and comments of 5 experts (IOC) as well as analyzing the quality of questionnaire on reliability. 


\section{Conclusion}

The results of development of Education Course Syllabus, Thai language major, according to Buddhism way of Thailand were as follows:

Part 1: Results of development of Education Course Syllabus, Thai language major, according to Buddhism way of Thailand obtained by using Taba's Approach (1972).

The results of development of Education Course Syllabus, Thai language major, according to Buddhism way of Thailand obtained by using Taba's Approach (1972) were consisted of curriculum objectives and learning objectives. The curriculum contents were determined and ordered. Subsequently, the duration was defined and experiences were selected and ordered. Determine what to be evaluated and methods of evaluation.

Part 2: Results of evaluation of efficiency of Education Course Syllabus, Thai language major, according to Buddhism way of Thailand obtained by using experimental research.

The results of evaluation of efficiency of Education Course Syllabus, Thai language major, according to Buddhism way of Thailand, performed by the experts showed that the curriculum was in overall in the highest level. When considering on each aspect, it was found that course description had the highest quality followed by educational management plan, curriculum objectives, curriculum quality assurance, and curriculum structure, evaluation, measurement, and principles, respectively.

Table 1. The quality of Education Course Syllabus, Thai language major, according to Buddhism way of Thailand by experts

\begin{tabular}{llll}
\hline List & mean & S.D. & interpretation \\
\hline Syllabus principles & 4.40 & 0.35 & highest \\
Objectives & 4.64 & 0.45 & highest \\
Syllabus structure & 4.60 & 0.29 & highest \\
Educational management plan & 4.80 & 0.45 & highest \\
Course description & 4.84 & 0.33 & highest \\
Criteria and assessment & 4.43 & 0.51 & highest \\
Curriculum Quality Assurance & 4.60 & 0.55 & highest \\
\hline Average & 4.62 & 0.42 & highest \\
\hline
\end{tabular}

Note. The result of the evaluation on efficiency of Course Syllabus, Thai language major, according to Buddhism way of Thailand conducted by the expert showed that the quality of this syllabus was, in overall, in the highest level at mean $=4.62$ and S.D. $=0.42$.

Table 2. State criteria for evaluating: Likert Scale

\begin{tabular}{lc}
\hline Interpretation & Score \\
\hline Highest & $4.21-5.00$ \\
High & $3.41-4.20$ \\
Average & $2.61-3.40$ \\
Low & $1.81-2.60$ \\
Lowest & $1.00-1.80$ \\
\hline
\end{tabular}

\section{Discussion}

1) Discuss on the results of development of Education Course Syllabus, Thai language major, according to Buddhism way of Thailand obtained by using Taba's Approach (1972) consisted of curriculum objectives and learning objectives. The curriculum contents were determined and ordered. Subsequently, the duration was defined and experiences were selected and ordered. Determine what to be evaluated and methods of evaluation. These were consistent with the results obtained by (Taba, 1972) proposing the procedures of curriculum development as follows: (1) Diagnose demands; (2) Determine the educational objectives as demanded by the 
society; (3) Select subject contents and knowledge that must be taught by teachers for providing demands met with necessity of the society; (4) Order procedures, amend, and improve selected contents; (5) Select learning experiences using for reinforcing contents and processes to be complete and consistent with objectives; (6) Organize, order procedures, amend, and improve learning experiences; (7) Evaluate the results of the curriculum that was consisted with the work of Sa-ngad Utranant (2004) proposing the procedures of curriculum development as follows: (1) analyze basic data; determine objectives; (3) Select and order contents; (4) Determine measurement and evaluation; (5) implement the curriculum; (6) Evaluate the results of curriculum utilization; (7) Amend and improve curriculum.

2) Discussion on the results of evaluation of efficiency of Education Course Syllabus, Thai language major, according to Buddhism way of Thailand, performed by the experts. The experts found that the curriculum was in overall in the highest level that was consistent with the work of (Taba, 1972) stated that the curriculum was consisted of 4 elements including general objectives and course objectives, contents and course hours, instructional processes, and learning results evaluation according to curriculum. In addition, it was also consistent with the work of (Khunakorn, 1995) who divided the elements of the curriculum into 5 elements including general objectives, course objectives, course hours, instructional processes, evaluation upon curriculum, and curriculum improvement. In addition, it was also consistent with the work of (Jewpanich, 2015) that (1) the PBL-DLL SoMe Model used for enhancing problem solving skills of undergraduate in education student, consists of 4 components which are 1) the analysis of the readiness of the input factors, 2) the process of the PBL-DLL SoMe Model, 3) the evaluation of the achievement of learning and problem solving skills (Output), and 4) the evaluation of the result between evaluating and feedback.

\section{Suggestions}

1) There should be some further researches on follow -up of the results of curriculum after implementation and the results in long-term implementation in order to study whether the students had development and changing on their Thai language usage and how.

2) There should be some further researches on curriculum development by utilizing concepts and techniques of preparing activities in other forms in order to discover the appropriate training format for various contexts.

3) There should be curriculum development conducted with students in other faculties of the university in order to develop and apply obtained knowledge and abilities on Thai language to learning and communication properly.

\section{Definitions}

1) Education Course Syllabus, Thai language major means a document defining the terms of experiences for using as the guidelines for ordering the experiences in order to enable learners of teaching profession to be progressed with knowledge on Thai language. The necessary elements of the curriculum were consisted of objectives divided into general objectives and course objectives, contents, learning experiences, facts and knowledge, concepts and principles, problem solving and creativity, physical skills, attitudes, values, and evaluation.

2) Buddhism way of Thailand means educational management for developing overall quality of life of the learners including morality, ethics, and life perception with intellect, wise, literacy, and other aspects of living emphasizing on eating, living, listening, and watching. It is the natural way of life and correct living in order to provide actual benefits by using the Buddhist principles as the guidelines for operation, managerial services in educational institutes, curriculum management, learner development activities, and other activities, in order to develop Thai youth on their behaviors, mentality, and intellect according to Three Studies.

\section{Acknowledgments}

This research was supported by Suan Sunandha Rajabhat University and National research council of Thailand. Special thanks you to all experts of SSRU who helped and supported this project.

\section{References}

Debaratanarajasuda. (1999). Includes lectures, educational in Princess Maha Chakri Sirindhorn of Thailand. Bangkok: Foundation of Princess Maha Chakri Sirindhorn.

Faculty of Education. (2006). Education Course Syllabus of Suan Sunandha Rajabhat University. Bangkok: Suan Sunandha Rajabhat University Printing.

Jewpanich, C., \& Piriyasurawong, P. (2015). Project-Based Learning Using Discussion and Lesson-Learned Methods via Social Media Model for Enhancing Problem Solving Skills. International Education Studies, 


\section{$8(6), 24$.}

Khunakorn, S. (1995). Curriculum and instruction (4th ed.). Bangkok: Chanuan Printing.

Leetheera, S. (2006). Effects of train the brain's ability to critical thinking by theory of intelligence Sternberg Hindenburg on the ability to critical thinking (Pratomsuksa 6 students, thesis. M.Ed., Srinakharinwirot University, Bangkok).

Likert, R. A. (1961). New Patterns of Management. New York: McGraw-Hill Book Company Inc.

Ministry of Education, Thailand. (2002). Basic Education Curriculum. B.E. 2544 (A.D. (2001) (Trans. Chavalit, M)). Bangkok: Express Transportation of Thailand.

Ministry of University Affairs. (2001). Policies and procedures for assessing the quality of higher education. Office of the Higher Education University Affairs.

Pongpaibul, P. (1997). "The model of teaching Buddha religion" in the heart of the Religious Education to foundation (pp. 111-112). Bangkok: Pikkhanate Printing Center.

Sakdanarong, N. (1996). The last straw. Bangkok: Ton or Grammy.

Taba, H. (1972). Curriculum Development: Theory and Practice. New York: Brace \& World Inc.

Vihokto, P. (2009). The synthetic of the pattern development of children's self-control Thailand. Bangkok: Division of Educational Research Department.

\section{Copyrights}

Copyright for this article is retained by the author(s), with first publication rights granted to the journal.

This is an open-access article distributed under the terms and conditions of the Creative Commons Attribution license (http://creativecommons.org/licenses/by/3.0/). 